\title{
On the Characteristics and the Development Significance of Hangzhou Lotus Culture
}

\author{
Hongbin Shi \\ School of Tourism, Zhejiang Business College, 310053 Hangzhou Zhejiang, China
}

\begin{abstract}
Lotus is the symbol of honesty, goodness, beauty and purity in the eyes of the Chinese people. The development of tourism in Hangzhou is inseparable from the lotus culture connotation. This paper analyzes the necessity to enhance the lotus culture in the city of Hangzhou, and discusses the Hangzhou Lotus Culture and its regional characteristics. The article indicates the further significance of the development of lotus culture tourism resources in Hangzhou.
\end{abstract}

Keywords. lotus; culture; Hangzhou; regional characteristics

Lotus also called water lily, is one of the earliest plants discovered in the world, and one of the representative survival plants on earth before the ice age. According to historical record, the history of lotus cultivation is very long, which can be traced up to 3000 years ago. Lotus also has its enormous economic value, its seeds, root, and leaf can be used for food, medicinal materials etc.. Lotus leaf can also be utilizated for making vests, ornamental crown, purse, and wrapping food in summer season. South from Hainan Island, north to Heilongjiang, east to Taiwan, and west to Xinjiang till north of the Tianshan Mountains, lotus is widely planted in China. From the perspective of "culture" to study and research flowers and plants, especially those famous flowers, is very popular in China, Japan etc.. The Japanese peer in this field also pay more attention to the lotus culture, such as Watanabe Dami, in his book titled The Charm of Hualian, he expounded the history, culture, literature, art, religion, philosophy of lotus, covering approximately half of its pages. The formation of the lotus culture complex, lies not only her practicality, but also her peerless delicate elegance, not to mention its noble temperament, and gracious moral character. A Northern Song Dynasty writer Zhou Dunyi in the Song of Lotus praised lotus "retains its cleanness and purity growing out of mud, posing elegantly without being flirtatious." This displays lotus rich and deep content.

\section{The necessity of promotion and pub- licity of lotus culture in Hangzhou}

\subsection{The lotus culture catering to the material and spiritual civilization of modern society}

Balance and harmony of material and spiritual needs has become the core of human survival and social development. Opinion of human and social progress has changed a great deal than that in the past. Enhancing the quality of life, improving the living standard, and the transformation of human society has become the goal of health and sustainable development today. Lotus is the symbol of honesty, goodness, and beauty in the eyes of the Chinese. She possesses unique natural beauty, known as the fairy in green, "its green leaves can stretch so far to the ruddy horizon, and bathed in sunshine are exceptionally pink lotus blossoms." Lotus is also known as queen of flowers. She grows in mud, yet never contaminates with it, and she floats on waving water, yet never dances with it. Lotus has been compared with those officials and people who have clean hands and pure heart for thousands of years. She is not only endowed on poetry, but also in the form of painting, so as to obtain the worship of Buddhist culture, and respected by Chinese people. Its delightful temperament influences people's daily life in various aspects and it has been formed into a kind of lotus culture since ancient time. Expanding and developing Hangzhou lotus cultural tourism resources, to meet people's material and spiritual needs is also an important part of the sustainable development strategy of Hangzhou tourism.

\subsection{The lotus culture has a profound impact on tourism industry innovation in Hangzhou}

Hangzhou is one of the seven ancient capitals of China, and richly endowed by nature conditions in the cultural heritage and traditions. The Liangzhu, $\mathrm{Wu}$ Yue culture, and the culture of the Southern Song Dynasty, plus the classical garden culture of West Lake, are all unparalleled 
treasures of Hangzhou. In the process of building Hangzhou into world famous city, we are supposed to make the local culture serve the economic construction, let the deep humanities spirit integrated in economic and social activities. Nowdays, the comparative advantage in the core elements of local culture has faded gradually, and the cultural development in different cities begins to assimilate. This increases the difficulty of regional culture exploring, and external market exploiting. Therefore, each city's travel strategy emphasis more on the local characteristics development and this kind of development has been gradually free from the natural condition of the city which used to focus on the center of production factors. It keeps a watchful eye more on the unique local cultural heritage. And the lotus culture as an important delegation of tourism human history of Hangzhou, with its ornamental and economic value is fully consistent with the development of the city and its industrial base, as well as economic geography, let alone conforms with its humanity spirit and traditional culture. In consequence, we should re-examine and fully release the lotus cultural tension, which will have a profound impact on Hangzhou tourism industry innovation and boosting.

\section{Hangzhou lotus culture and its region- al characteristics}

The uniqueness of the culture is a very important factor to assess its value. Tourism product must reflect the unique regional culture, and it will lose the market attraction, if one just copy cultural tourism products without connotation at will. If the knowledge components of tourism cultural products cannot meet the needs of individual consumers, or the knowledge composition aging due to lack of innovation, the more you produce, the greater you loss. That is to say, the personalization and diversification of production mode is the essential characteristics of cultural tourism products, which must be taken seriously in a long time.

\subsection{Lotus is the elements of garden landscape, and park setting in Hangzhou West Lake}

Quite a few beauty spots are famous for the lotus plantation in Chian, such as Daming Lake in Ji'nan, Lili Hill in Guangdong etc.. Lotus view in the West Lake, however, comes out at the top for its unique cultivation techniques and longer cultivation history. Yang Zhongbao native to Shanghai wrote the first book The Varieties of Lotus during Jiaqing year in Qing dynasty, he mentioned the Hangzhou Red breed, and said "it's my best loved lotus."

The summer scene of West Lake is very special with colorful lotus blossoms decorating much of its surface. Gentle breeze-ruffled lotus at Quyuan Garden, a boundless stretch of pink, white and yellow lotus flower set off by the green lotus leaves, "stretching so far to the ruddy horizon, bathed in sunshine are exceptionally pink lotus blossoms". This is the most beautiful dawn view in the West Lake. With the area of 130 acres, lotus flowers were planted in several different sections in the Lake, such as Xiling Bridge, Yue Lake, The Wind and Rain Pavilion,
Inner Lake, and North Lake, among all these areas, the most popular watching spots are the broken bridge section, Zhanbi Pavilion, Autumn moon at the calm lake and Breeze-ruffled lotus at Quyuan Garden, the latter was Southern Song Dynasty royal wine workshop, known as the "Breeze-ruffled lotus at Quyuan Garden". Every summer, when lotus in full bloom, fragrant wine mingled with gentle breeze, make it one of the Ten Views of the West Lake during the Southern Song Dynasty. When you wander down to the Zhanbi Pavilion, sitting on the stone boat, talking over tea and lotus leaf porridge, looking at a boundless stretch of pink, white and yellow lotus flower set off by the green lotus leaves, which is a kind of comfortable pleasant enjoyment of the scene.

Lotus in West Lake is kind of water-scape. From full view, it looks like a natural decration here and there, in a contrast to the whole, lotus is the main part of a garden or park. There were four gardens and parks where local people used to enjoy this queen of the waterlily. They are Breeze-ruffled lotus at Quyuan Garden; the Socity of the Lake and Mountain; Watching lotus at natural pond; Viewing lotus at Pine Chamber.

The West Lake Lotus Museum is located at Yingxun Hall in Quyuan Garden. The displaying gives a panorama of its original history, varieties, distribution, behoof etc. in words and pictures.

It also tells us its relationship with Buddhism and how to appreciate them in artistic way, and other relevant knowledge of the flower. The displaying helps people further understand the lotus, enjoy the lotus, and advertise its cultural connotation. The broken bridge is an ideal spot to admire the lotus. The pagoda on the Baochu Hill sets her figure off to advantage, constituting a beautiful landscape. In the sunset, when sitting on the electric boat, cruising between the lotus gives us a view of "a man within the boat, and the boat within the lotus", what a poetic picture! To the northeast of the Xiling Bridge, when lotus are in full bloom, its green leaves are dancing in the calm lake against the beautiful girls and charming boys as well as nature. They are dating, falling in love, pleasing to each eyes and heart and finally losting themselves in the lotus. This romantic scenes intensify and prove Hangzhou an oriental leisure capital and attracts millions and millions tourits both home and abroad.

\subsection{Anthem for lotus has a long history in Hang- zhou}

People are familiar with lotus by means of its practicability. With the development of society and the progress of civilization, it went deep into people's spiritual world because of its gorgeous looking and graceful bearing. Throughout the ages, from the emperor, literati to ordinary people all have deep feelings for lotus. The prototype of lotus culture appeared from the Western Zhou Dynasty to the Spring and Autumn Warring States period (11 century BC). "On the bank of the pand, grows lotus and cattail; seeing a handsome man, how wonderful can I encounter him" is the earliest version about lotus from The Songs · Chen Feng. Early at that time, people compared lotus and cattail with man and woman, and fell in 
love and lived together forever. "There are lush green Fusu in the mountain, there are glamorous lotus in the pond; did not see the handsome Zhidu, but met you little maniacs instead" comes from The Songs · Zheng Feng, another songs to praise elegant, colourful and dazzling lotus flower.

Hangzhou has been a famous historical and cultural city, and lived numerous men of literature and writing who write a plenty of poetry about lotus since ancient time. Tang Dynasty governor poet Li Bai composed a poem entitled Yue lady Word, it goes like this "there is a lotus seeds picking girl in Ye Creek, whenever and wherever sees guests, she would fled into the lotus bushes, singing and laughing, pretend shy and refuse to come out." Another poet Bai Juyi wrote: "The town is surrounded by Lotus ponds for thirty mile, under the green vines, there are feasts in dancing and singing, geishas are sitting in boats moored in red lotus flower everywhere". Northern Song Dynasty governor poet Su Dongpo wrote: "Spreads lotus across lakes and marshes, subtle franrance floats in the moonlight mellow." Poet Liu Yong composed: "Sweet-scented osmanthus blossoms in the midautumn, fragrant lotus are in full bloom in ten miles". For centuries, the lotus has inspired a large numbers of poets. Off all the poems that praise lotus, the most famous is perhaps the one composed by the noted Southern Song poet Yang Wanli. It is entitled The West Lake in Midsummer "After all it's the West Lake in summer hot, displaying scenes no other seasons have got; Green lotus leaves stretch so far to the ruddy horizon, bathed in sunshine are exceptionally pink lotus blossoms" describing the beautiful and vivid lotus scenery in West Lake.

Shi Naian, auther of the classical novel, had a song Prelude to Water Melody - West Lake: The kingdom of $\mathrm{Wu}$ is the most ideal place to taste the delicious lotus roots in summer and smell fragrance of chrysanthemum and lotus in autumn. Ming Dynasty politician Yu Qian wrote a poem for his homeland: "Weeping willows are dancing outside Yongjin Gate of Hangzhou, the shimmering ripple upsurges in the West Lake; pretty lady in silk skirt paddles the boat, mandarin duck flies over the lotus seeds picking canoe". The literary scholar Zhang Dai in Ming Dynasty said, "she looks a little drunk, and breaks into a smile; what is causing the charming lotus? Warm breeze on the lake." Zhong Xi in his Tour of West Lake with friends: The vast, calm lake is reaching as high as to the sky; lotus and weeping willows are meandering through a misty autumn." The Qing Dynasty Shen Deqian wrote: Lotus pond and pine cottage poetry, it goes like "Attending six class of Buddhism, enjoying the beautiful lotus flower, you may live as long as one hundred years old."

\subsection{Lotus culture has its strong religious in- flunce in Hangzhou}

In religion world, the lotus was promoted to a divine status. When you go to a temple, you always find that Shakyamuni and Godess of mercy are sitting on the lotus because of its purities, thus Buddha may not affected by the temptation of common customs and maintain the
Buddha nature. In China floral kingdom, there is no other flower as lotus that abtained such a holy aura in spirits and such deep culture content. Lotus has been considered as the queen of the flower for its noble and holy image for thousand years. Back to Tang Dynasty, local people celebrate the Lotus Festival, which is not quite available for other flowers in China. The governor of Zhejiang, Li Wei in Qing Dynasty built a temple named Goddess of Flower on the north shore of West Lake in Hangzhou, dedicating to the goddess of the lotus flower. According to the lunar calendar, June 24 is the birthday of lotus. It is the time and season to enjoy the green lotus leaves stretch so far to the ruddy horizon. There are varieties of lotus species in Hangzhou, which are with single petal, double petal and double stalks, in red, purple, white and yellow. During this very season, tourists would have a cruise on the lake and watch lotus dancing like a flower fairy in a breeze blowing. Almost all the citizen of Hangzhou would like to go to the Goddess of Flower Temple, or take part in a garden party, enjoy the glorious lotus flower in the Lake. They would have their meals in the boat, listen to music and theatergoing on the Lake. The highlight of the activities is right in the evening, they called it a lotus lantern ceremony, at that moment, the whole Lake were covered with thousands of lotus lamp, floating, flickering, and which may calling their ancestors soul back. If you are interested in having a dinner lakeside, you may go to those famous local restaurant, not only taste the delicious Hangzhou cuisine, but also watch local opera and local talking and singing show. Hangzhou has been the Buddhist paradise and the home of lotus in southeast China since ancient times. Buddha and Bodhisattva are always being seen sitting on the lotus stand or what they called the auspicious position. In the book of Mahavairocana Tantra, it is said: "Putting your left foot on the right leg, and right foot on the left, that's lotus gesture; single foot to the right, it is auspicious position." According to the Buddhist sutras, the lotus can test your self-cultivation extent, as long as your sincerity to Buddha, the western seven tresures pool would emerge a pure lotus flower, the more you cultivate, the more the lotus appear, if failed, the flower would withered. When you go to visit the most well known Lingyin Temple in Hangzhou, you will see the main peak of the Flying Hill, which is called the Lotus Peak. Standing alone at the top, boulders beyong the boulders, spreading all directions, that is lotus. Yuan Hongdao depicted in his Entitling the Flying Peak "as white as jade, as green as lotus leave."

\subsection{Lotus culture and celebrity charm in Hang- zhou}

Since ancient time, men of literature and writing has admired lotus for its elegance and fairness, slim and graceful gesture, refreshing and fragrance, arrogant and haughty. From the emperor to celebrity, such as Tang Xuanzong Li Longji, the Qing Emperor Qianlong and outstanding writer and poet Bai Juyi, Yang Wanli, Zhou Dunyi and Zhu Ziqing, the famous painter Zhang Daqian, Li Kuchan, etc.. The former mayor of Hangzhou, Bai Juyi loved lotus for lifetime. During his term in Hang- 
zhou, he organized the local labor force to build the Bai causeway with lotus along each side. In summer, "The east to the scenic Qiatang Lake I love best; strolling the willow-shaded white-sand dyke I enjoy most". Before he bid farewell to the city, he said: "the future seems in miserable journey, the orchestral sound see me off, pretty lady could not retain mayor, because the emperor just let me stay here for three years. Geisha are dancing and singing in the boat, which parked in the lotus-shaded bank, what I miss the most, is the West Lake in Hangzhou." Another 2.8-kilometer-long Su causeway identified with the Northern Song Dynasty poet $\mathrm{Su}$ Dongpo. The causeway was built of the dredging of West Lake when he organized a large-scale dredging of the lake during his term as the city's governor. Seen nearby is three more-than-400-year-old stone pagodas sticking out of the lake, one of the Ten Views of the West Lake "Three Ponds Mirroring the Moon". Within the circle of the towers, water vegetations are not allowed, including lotus, cattail and gorgon fruit. Southern Song Dynasty poet Wanli Yang wrote more than 20 thousand poetry lifetime, among them, the most brilliant verses are those about lotus. He studied lotus meticulously, and describe them clearly and sweetly, lively and vividly with feeling and setting happily blended. In the song of Pool, he wrote: "Silent spring cherish trickle, as water love fine soft shade. Lotus just buds, long Dragonfly stand on top." Lotus and dragonfly are fresh and elegant. And there is a bridge: "Xiao sitting lotus leaf green Ping green pool, thousands of green covering red. The air element and no see, see wave back to fly." The combination of static and dynamic is natural interest.

\subsection{Rich and colorful lotus cooking culture in Hangzhou}

Chinese cooking and food has its long history. Lotus seeds were widely consumed in the middle period of Neolithic age, it was considered as the main food for human at that time. Lotus is one of the earliest edible plants discoved by man and has a history of thousands of years. The lotus culture affects the diet culture and they integrate and promote each other, creating a series of abundant lotus cuisine. The most distinguished lotus dish is called the beggar's chicken, which is harmony in color, flavor, taste and shape. It is a kind of roasting chicken, wrapped in lotus leaf, and baked with Shaoxing vinasse mud. When lotus leaves are mingled with chicken and wine fragrance, you can imagine how dilicious they are, and it is one of the most famous traditional Chinese dishes. And, of course, there is an interesting story behind it. One summer day, Emperor Qianlong disguised himself and went out into the Lakeside Park to do some sightseeing around the West Lake with his little eunuch. It was a little bit hot day, and the lunch seemed not prepared as usual. Suddenly, a burst of faint scent fluttered from a cluster of bushes, both the emperor and eunuch were attracted and followed the smell, they found a beggar who is baking a yellow, fragrant mud pie. When he smashed it, it was a chicken wapped with green lotus leaf. It was lunch time and the emperor was hungry, he had the little eunuch asked for a piece meat and it turned out the most tender and tasteful chicken he had ever had. From then on, whenever he had an inspection tour or common visiting in Hangzhou, the emperor would always have this dish and named it "the beggar's chicken". It's quite common to cook the local dishes with lotus leaf, lotus seeds and roots, such as chicken in lotus seeds, pork leg in lotus seeds, fish in lotus, pork chop with lotus roots soup, steamed pork with lotus leaf, steamed chicken wrapped in lotus leaf, duck in litchi and lotus leaf, shredded fish in lotus, ham with green lotus leaf etc. to name just few. Those dishes with lotus are known to every family in Hangzhou. Some lotus foods serve as Hangzhou specialities, such as lotus root starch, lotus roots with glutinous rice, lotus seeds in sweet osmanthus, moon cake in lotus etc. they taste a little bit sweet, indicating happiness, cool and content.

\section{The significance of developing lotus cultural resources in Hangzhou}

With the improvement of metropolitan culture, the selection and development mode of city industry can proceed and express not only requireing a corresponding industrial economy to interact and expanse, but also a positive spirit from its citizen. People love lotus for four reasons, first, lotus is a native and special products to Chinese people, it is very popular to everyone and every family here, while in the western countries, few lotus plants are cultivated and few people has an idea of lotus effect. Second, it is harmony in rhyme, state, color and smell. It holds the name of "beauty" or "independent spirit"on land or water. The former Premier Zhou Enlai loves it for a lifetime long. Third, the plants are treasure all over, it has ornamental as well as economic value. Last, lotus bears a kind of cultural and ideological progress and cultural tradition which are long-standing and wellestablished in Chinese people's heart.

We are carrying out establishing what we called "complete harmony and open door unprejudiced policy" in Hangzhou city. The key point is how to develop tourism industry and humanistic spirit in a more harmonious way. And such atmosphere is quite necessary in the process of promoting the city's cultural taste, what is more, it must go with humanistic care and reflect the new humanistic spirit. The more the cultural feature it contains, the stronger the city's aggregation it has.

Hangzhou should take full advantage of abundant lotus cultural heritage, and distinguish it from that of exterior zone. Therefore, we are going to deep develop the lotus cultural tourism product, and layout a large number of lotus culture-oriented travel route. We are going to hold international lotus festival, and enjoy the sight of lotus, taste them and comment them at the same time. This is the new path to reveal and excavate the potential of leisure tourism image and the development of tourism industry in Hangzhou

\section{References}


1. Li Wei (Qing). Annals of West Lake [M]. Shanghai: Shanghai Ancient Books Publishing House, 1995.

2. Zhang Dai (Ming), West Lake Dream [M]. Beijing: Beijing Press.2004.

3. Shi Hongbin. The Urban Tourism of Hangzhou [M]. Hangzhou: Zhejiang Gongshang University Press, 2010.
4. Dong Shibing. 300 First Ancient Poetry [M]. Beijing: Times Literary Publishing House. 2012.

5. Bi Shuchang. Japanese lotus varieties [J]. Flower Plant \& Penjing, 2000, (7):59-62.

6. Yan CI mage. Buddhist Ritual Introduction [M]. Beijing: Religious and Culture Publishing House, 1999. 